\title{
The global proof of the Polak-Ribière-Polak algorithm under the YWL inexact line search technique
}

Xiangrong $\mathrm{Li}^{1}$, Tianshan Yang ${ }^{2}$ and Xiaoliang Wang ${ }^{3 *}$ (D)

\section{"Correspondence:}

xliangwang@126.com

${ }^{3}$ School of Mathematical Sciences,

Dalian University of Technology,

Dalian, P.R. China

Full list of author information is

available at the end of the article

\begin{abstract}
This paper presents a new proof method about the paper (Yuan et al. in Appl. Math. Model. 47:811-825, 2017). In the proof, the global convergence of the

Polak-Ribière-Polak algorithm is established without these two assumptions $d_{k}^{\top} g_{k}<0$ and $g_{k+1} d_{k} \leq-\sigma_{1} g_{k}^{T} d_{k}$ which are needed in the above paper. This means that this paper has the same results under weaker conditions. More dimension functions for practical problems are tested to show the performance of the modified algorithm and the normal algorithm. An application of the fact engineering model is done to show the effectiveness of the given conjugate gradient algorithm.
\end{abstract}

MSC: $90 C 26$

Keywords: PRP method; Global convergence; WWP line search; Nonconvex functions; Muskingum model

\section{Introduction}

Consider

$$
\min \left\{f(x) \mid x \in \Re^{n}\right\},
$$

where $f: \Re^{n} \rightarrow \Re$ and $f \in C^{2}$. The Polak-Ribière-Polak (PRP) conjugate gradient (CG) method $[16,17]$ for $(1.1)$ is designed by the following iterative formula:

$$
x_{k+1}=x_{k}+\alpha_{k} d_{k}, \quad k=0,1,2, \ldots,
$$

where $x_{k}$ is the $k$ th iterative point, $\alpha_{k}$ is a stepsize, and $d_{k}$ is the search direction defined by

$$
d_{k+1}= \begin{cases}-g_{k+1}+\beta_{k}^{\mathrm{PRP}} d_{k}, & \text { if } k \geq 1 \\ -g_{k+1}, & \text { if } k=0,\end{cases}
$$

where $g_{k+1}=\nabla f\left(x_{k+1}\right)$ is the gradient of $f(x)$ at point $x_{k+1}, \beta_{k}^{\text {PRP }} \in \Re$ is a scalar defined by

$$
\beta_{k}^{\mathrm{PRP}}=\frac{g_{k+1}^{T}\left(g_{k+1}-g_{k}\right)}{\left\|g_{k}\right\|^{2}},
$$

(c) The Author(s) 2019. This article is distributed under the terms of the Creative Commons Attribution 4.0 International License (http://creativecommons.org/licenses/by/4.0/), which permits unrestricted use, distribution, and reproduction in any medium, provided you give appropriate credit to the original author(s) and the source, provide a link to the Creative Commons license, and indicate if changes were made. 
where $g_{k}=\nabla f\left(x_{k}\right)$ and $\|\cdot\|$ denotes the Euclidean norm. The theory analysis and the numerical performance about the PRP method have been done by many scholars (see [2, 3 , 17-19, 22] etc.), and many modified algorithms based on the normal PRP formula have been proposed to make a great progress $([6,8-13,20,21,23-25,27,29,30]$ etc.). The well-known weak Wolfe-Powell (WWP) inexact line search for $\alpha_{k}$ satisfies

$$
f\left(x_{k}+\alpha_{k} d_{k}\right) \leq f_{k}+\delta \alpha_{k} g_{k}^{T} d_{k}
$$

and

$$
g\left(x_{k}+\alpha_{k} d_{k}\right)^{T} d_{k} \geq \sigma g_{k}^{T} d_{k}
$$

where $\delta \in(0,1 / 2)$ and $\sigma \in(\delta, 1)$. At present, the global convergence of the PRP CG algorithm for nonconvex functions under the WWP line search is a well-known open problem in optimization fields, and the counterexamples of $[3,18]$ tell us the reason. Motivated by the idea of [3], a modified WWP line search technique is given by Yuan et al. [28] and it is designed by

$$
f\left(x_{k}+\alpha_{k} d_{k}\right) \leq f_{k}+\delta \alpha_{k} g_{k}^{T} d_{k}+\alpha_{k} \min \left[-\delta_{1} g_{k}^{T} d_{k}, \delta \frac{\alpha_{k}}{2}\left\|d_{k}\right\|^{2}\right]
$$

and

$$
g\left(x_{k}+\alpha_{k} d_{k}\right)^{T} d_{k} \geq \sigma g_{k}^{T} d_{k}+\min \left[-\delta_{1} g_{k}^{T} d_{k}, \delta \alpha_{k}\left\|d_{k}\right\|^{2}\right],
$$

where $\delta \in(0,1 / 2), \delta_{1} \in(0, \delta)$, and $\sigma \in(\delta, 1)$. Here we call it YWL line search. It is used for not only the PRP method but also the BFGS quasi-Newton method (see $[26,28]$ in detail). In the case $\min \left[-\delta_{1} g\left(x_{k}\right)^{T} d_{k}, \delta \alpha_{k}\left\|d_{k}\right\|^{2}\right]=\delta \alpha_{k}\left\|d_{k}\right\|^{2}$, the global convergence of the PRP algorithm is established including the conditions $d_{k}^{T} g_{k}<0$ and $g_{k+1} d_{k} \leq-\sigma_{1} g_{k}^{T} d_{k}$. This paper will make a further study and obtain the global convergence similar to [28] without the conditions $d_{k}^{T} g_{k}<0$ and $g_{k+1} d_{k} \leq-\sigma_{1} g_{k}^{T} d_{k}$ by another proof way. This paper has the following features:

- The PRP algorithm for nonconvex functions with the YWL line search has the global convergence.

- The global convergence is established under weaker conditions than those of the paper [28].

- Larger scale dimension problems are tested to show the performance of the proposed algorithm.

The next section states the algorithm and the global convergence of the presented algorithm. Section 3 does the experiments including the normal unconstrained optimization and an engineering problem. One conclusion is given in the last section.

\section{PRP algorithm and global convergence}

The PRP algorithm with the modified WWP line search for nonconvex functions is listed as follows. 
Algorithm 1 (The PRP CG algorithm under the YWL line search rule)

Step 1: Choose an initial point $x_{1} \in \mathfrak{R}^{n}, \varepsilon \in(0,1) \delta \in\left(0, \frac{1}{2}\right), \delta_{1} \in(0, \delta), \sigma \in(\delta, 1)$. Set $d_{1}=$ $-g_{1}=-\nabla f\left(x_{1}\right), k:=1$.

Step 2: If $\left\|g_{k}\right\| \leq \varepsilon$, stop.

Step 3: Compute the step size $\alpha_{k}$ using the YWL line search rule (1.6) and (1.7).

Step 4: Let $x_{k+1}=x_{k}+\alpha_{k} d_{k}$.

Step 5: If $\left\|g_{k+1}\right\| \leq \varepsilon$, stop.

Step 6: Calculate the search direction

$$
d_{k+1}=-g_{k+1}+\beta_{k}^{\mathrm{PRP}} d_{k}
$$

Step 7: Set $k:=k+1$, and go to Step 3 .

The normal assumptions for the nonconvex functions are needed as follows.

\section{Assumption i}

(A) The defined level set $L_{0}=\left\{x \mid f(x) \leq f\left(x_{0}\right)\right\}$ is bounded.

(B) Let $f(x)$ be twice continuously differentiable and bounded below, and the gradient function $g(x)$ is Lipschitz continuous, namely there exists a constant $L>0$ satisfying

$$
\|g(x)-g(y)\| \leq L\|x-y\|, \quad x, y \in \Re^{n} .
$$

\section{Remark}

(1) Define a case by Case $i$ : $\min \left[-\delta_{1} g\left(x_{k}\right)^{T} d_{k}, \delta \alpha_{k}\left\|d_{k}\right\|^{2}\right]=\delta \alpha_{k}\left\|d_{k}\right\|^{2}$. This case means that

$$
-\delta_{1} g\left(x_{k}\right)^{T} d_{k} \geq \delta \alpha_{k}\left\|d_{k}\right\|^{2} \geq 0
$$

which can ensure that the modified WWP line search (1.6) and (1.7) is reasonable (see Theorem 2.1 in [28]). Then Algorithm 1 is well defined.

(2) In [28], the global convergence of Algorithm 1 is established for Case i, and it needs not only Assumption i conditions but also

$$
d_{k}^{T} g_{k}<0
$$

and

$$
g_{k+1} d_{k} \leq-\sigma_{1} g_{k}^{T} d_{k}
$$

In this paper, we will give another proof way only needing Assumption i.

(3) Assumptions i(A) and i(B) imply that there exists a constant $G^{*}>0$ such that

$$
\|g(x)\| \leq G^{*}, \quad x \in L_{0} .
$$

Lemma 2.1 Let Assumption i hold. If there exists a positive constant $\epsilon_{*}$ such that

$\left\|g_{k}\right\| \geq \epsilon_{*}, \quad \forall k$ 
then we can deduce that there exists a constant $D^{*}$ satisfying

$$
\left\|d_{k}\right\| \leq \omega^{*}, \quad \forall k .
$$

Proof By (1.6), we get

$$
\begin{aligned}
f\left(x_{k}+\alpha_{k} d_{k}\right) & \leq f_{k}+\delta \alpha_{k} g_{k}^{T} d_{k}+\alpha_{k} \min \left[-\delta_{1} g_{k}^{T} d_{k}, \delta \frac{\alpha_{k}}{2}\left\|d_{k}\right\|^{2}\right] \\
& \leq f_{k}+\delta \alpha_{k} g_{k}^{T} d_{k}-\alpha_{k} \delta_{1} g_{k}^{T} d_{k} \\
& =f_{k}+\left(\delta-\delta_{1}\right) \alpha_{k} g_{k}^{T} d_{k},
\end{aligned}
$$

then the following inequality

$$
-\left(\delta-\delta_{1}\right) \alpha_{k} g_{k}^{T} d_{k} \leq f\left(x_{k}\right)-f\left(x_{k+1}\right)
$$

holds. Using Assumption $\mathrm{i}(\mathrm{A})$ and summing these inequalities from $k=0$ to $\infty$, we have

$$
\delta \sum_{k=0}^{\infty}\left[-\left(\delta-\delta_{1}\right) \alpha_{k} g_{k}^{T} d_{k}\right]<\infty
$$

Using Step 6 of Algorithm 1 and setting $s_{k}=x_{k+1}-x_{k}=\alpha_{k} d_{k}$, we have

$$
\begin{aligned}
\left\|d_{k+1}\right\| & \leq\left\|g_{k+1}\right\|+\left|\beta_{k}^{\mathrm{PRP}}\right|\left\|d_{k}\right\| \\
& \leq\left\|g_{k+1}\right\|+\frac{\left\|g_{k+1}\right\|\left\|g_{k+1}-g_{k}\right\|}{\left\|g_{k}\right\|}\left\|d_{k}\right\| \\
& \leq G^{*}+\frac{G^{*} L^{*}}{\left\|g_{k}\right\|}\left\|s_{k}\right\|\left\|d_{k}\right\| \\
& \leq G^{*}+\frac{G^{*} L^{*}}{\epsilon_{*}}\left\|s_{k}\right\|\left\|d_{k}\right\|,
\end{aligned}
$$

where the third inequality follows (2.2) and (2.3), and the last inequality follows (2.4). By the definition of Case i, we get

$$
d_{k}^{T} g_{k} \leq-\frac{\delta}{\delta_{1}} \alpha_{k}\left\|d_{k}\right\|^{2}
$$

Thus, by (2.6), we get

$$
\sum_{k=0}^{\infty}\left\|s_{k}\right\|^{2}=\sum_{k=0}^{\infty} \alpha_{k}\left(\alpha_{k}\left\|d_{k}\right\|^{2}\right) \leq \frac{\delta_{1}}{\delta\left(\delta-\delta_{1}\right)}\left[\left(\delta-\delta_{1}\right) \sum_{k=0}^{\infty}\left(-\alpha_{k} g_{k}^{T} d_{k}\right)\right]<\infty .
$$

Then we have

$$
\left\|s_{k}\right\| \rightarrow 0, \quad k \rightarrow \infty
$$


This implies that there exist a constant $\varepsilon \in(0,1)$ and a positive integer $k_{0} \geq 0$ satisfying

$$
\frac{G^{*} L^{*}\left\|s_{k}\right\|}{\epsilon_{*}} \leq \varepsilon, \quad \forall k \geq k_{0} .
$$

So, by (2.7), for all $k>k_{0}$, we obtain

$$
\begin{aligned}
\left\|d_{k+1}\right\| & \leq G^{*}+\varepsilon\left\|d_{k}\right\| \\
& \leq G^{*}\left(1+\varepsilon+\varepsilon^{2}+\cdots+\varepsilon^{k-k_{0}-1}\right)+\varepsilon^{k-k_{0}}\left\|d_{k_{0}}\right\| \\
& \leq \frac{G^{*}}{1-\varepsilon}+\left\|d_{k_{0}}\right\| .
\end{aligned}
$$

Let $\omega^{*}=\max \left\{\left\|d_{1}\right\|,\left\|d_{2}\right\|, \ldots,\left\|d_{k_{0}}\right\|, \frac{G_{b}}{1-\varepsilon}+\left\|d_{k_{0}}\right\|\right\}$. Therefore, we get

$$
\left\|d_{k}\right\| \leq \omega^{*}, \quad \forall k \geq 0
$$

The proof is complete.

Theorem 2.1 Let the conditions of the above lemma hold. Then the following relation

$$
\lim _{k \rightarrow \infty} \inf \left\|g_{k}\right\|=0
$$

holds.

Proof Suppose that (2.9) does not hold, we can deduce that there exists a constant $\epsilon_{*}>0$ such that

$$
\left\|g_{k}\right\| \geq \epsilon_{*}, \quad \forall k
$$

Using Lemma 2.1, we get (2.5). By a way similar to (2.6) and using the case $-\delta_{1} g\left(x_{k}\right)^{T} d_{k} \geq$ $\delta \alpha_{k}\left\|d_{k}\right\|^{2}$, we have

$$
\begin{aligned}
\frac{\delta-\delta_{1}}{\delta_{1}} \delta\left\|\alpha_{k} d_{k}\right\|^{2} & \leq-\frac{\delta-\delta_{1}}{\delta_{1}} \delta_{1} \alpha_{k} d_{k}^{T} g_{k} \\
& =-\left(\delta-\delta_{1}\right) \alpha_{k} g_{k}^{T} d_{k} \\
& \rightarrow 0, \quad k \rightarrow \infty,
\end{aligned}
$$

which generates

$$
\left\|\alpha_{k} d_{k}\right\|^{2} \rightarrow 0, \quad k \rightarrow \infty .
$$

Then we discuss the above relation by the following cases.

Case 1: $\left\|d_{k}\right\| \rightarrow 0, k \rightarrow \infty$. By (3.1), (2.3), (2.2), and (2.10), we have

$$
\begin{aligned}
0 & \leq\left\|g_{k+1}\right\| \\
& =\left\|-d_{k+1}+\beta_{k}^{\mathrm{PRP}} d_{k}\right\|
\end{aligned}
$$




$$
\begin{aligned}
& \leq\left\|d_{k+1}\right\|+\frac{\left\|g_{k+1}\right\|\left\|g_{k+1}-g_{k}\right\|}{\left\|g_{k}\right\|}\left\|d_{k}\right\| \\
& \leq\left\|d_{k+1}\right\|+\frac{G^{*} L\left\|\alpha_{k} d_{k}\right\|}{\epsilon_{*}}\left\|d_{k}\right\| \\
& \rightarrow 0, \quad k \rightarrow \infty .
\end{aligned}
$$

Then we get (2.9).

Case 2: $\alpha_{k} \rightarrow 0, k \rightarrow \infty$. By (1.7), Remark (1), and the Taylor formula, we get

$$
\begin{aligned}
g_{k}^{T} d_{k}+O\left(\left\|\alpha_{k} d_{k}\right\|^{2}\right) & =g\left(x_{k}+\alpha_{k} d_{k}\right)^{T} d_{k} \\
& \geq \sigma d_{k}^{T} g_{k}+\min \left[-\delta_{1} g_{k}^{T} d_{k}, \delta \alpha_{k}\left\|d_{k}\right\|^{2}\right] \\
& \geq \sigma d_{k}^{T} g_{k} .
\end{aligned}
$$

Combining with the case $-\delta_{1} g\left(x_{k}\right)^{T} d_{k} \geq \delta \alpha_{k}\left\|d_{k}\right\|^{2}$ leads to

$$
\begin{aligned}
O\left(\left\|\alpha_{k} d_{k}\right\|^{2}\right) & \geq-(1-\sigma) d_{k}^{T} g_{k} \\
& \geq \frac{\delta(1-\sigma)}{\delta_{1}} \alpha_{k}\left\|d_{k}\right\|^{2} .
\end{aligned}
$$

So we have

$$
O\left(\alpha_{k}\right) \geq \frac{\delta(1-\sigma)}{\delta_{1}} .
$$

This contracts the case $\alpha_{k} \rightarrow 0(k \rightarrow \infty)$. Then we also obtain (2.9). All in all, we always have (2.9). The proof is complete.

\section{Numerical results}

In this section, we do the numerical experiments of the given algorithm and the normal PRP algorithm for large scale unconstrained optimization problems and these problems are the same of the paper [28] which are from [1,7] with the given initial points and are listed in Table 1, where the same results are not given anymore. Furthermore we also do an experiment about the fact engineering problem model by the given algorithm. Now we test them and give the results as follows.

\subsection{Normal unconstrained optimization problems}

To clearly show the normal PRP algorithm, its detailed steps are presented as follows.

Table 1 Tested problems

\begin{tabular}{llcll}
\hline No. & Problem & No. & Problem & Character \\
\hline 1 & Extended Penalty Function & 9 & EDENSCH Function (CUTE) & These sixteen tested \\
2 & Extended Cliff Function & 10 & STAIRCASE S1 Function & functions come \\
3 & Extended Hiebert Function & 11 & LIARWHD Function (CUTE) & from practical \\
4 & A Quadratic Function QF2 Function & 12 & DIXON3DQ Function (CUTE) & problems such as \\
5 & Extended EP1 Function & 13 & FLETCHCR Function (CUTE) & the academic \\
6 & Extended Tridiagonal-2 Function & 14 & COSINE Function (CUTE) & problems or \\
7 & ARWHEAD Function (CUTE) & 15 & BIGGSB1 Function (CUTE) & engineer problems. \\
8 & EG2 Function (CUTE) & 16 & Scaled Quadratic SQ1 Function & \\
\hline
\end{tabular}


Algorithm 2 (The normal PRP CG algorithm)

Step 1: Choose an initial point $x_{1} \in \mathfrak{R}^{n}, \varepsilon \in(0,1) \delta \in\left(0, \frac{1}{2}\right), \sigma \in(\delta, 1)$. Set $d_{1}=-g_{1}=$ $-\nabla f\left(x_{1}\right), k:=1$.

Step 2: If $\left\|g_{k}\right\| \leq \varepsilon$, stop.

Step 3: Compute the step size $\alpha_{k}$ using the WWP line search rule (1.4) and (1.5).

Step 4: Let $x_{k+1}=x_{k}+\alpha_{k} d_{k}$.

Step 5: If $\left\|g_{k+1}\right\| \leq \varepsilon$, stop.

Step 6: Calculate the search direction

$$
d_{k+1}=-g_{k+1}+\beta_{k}^{\mathrm{PRP}} d_{k}
$$

Step 7: Set $k:=k+1$, and go to Step 3 .

The following Himmeblau stop rule and all parameters are the same to those of the paper [28].

Stop rules: If $\left|f\left(x_{k}\right)\right|>e_{1}$, let stop $1=\frac{\left|f\left(x_{k}\right)-f\left(x_{k+1}\right)\right|}{\left|f\left(x_{k}\right)\right|}$, or stop $1=\left|f\left(x_{k}\right)-f\left(x_{k+1}\right)\right|$. If the conditions $\|g(x)\|<\epsilon$ or stop $1<e_{2}$ hold, the program stops, where $e_{1}=e_{2}=10^{-5}, \epsilon=10^{-6}$.

Parameters: $\delta=0.1, \delta_{1}=0.05, \sigma=0.9$.

Dimension: $30,000,60,000$, and 120,000 variables.

Experiments: All the programs were written in MATLAB 7.10 and run on a PC with a $1.80 \mathrm{GHz} \mathrm{CPU}$ and $4.00 \mathrm{~GB}$ of memory running the Windows 7 operating system.

Other cases: The program is also stopped if the number of iterations is greater than 1200 .

The step size $\alpha_{k}$ in the line search is accepted if the search number is greater than 10.

The columns of Table 2 have the following meanings:

No.: the number of tested problems. Dim: the dimension of tested problem.

Cputime: the CPU time in seconds. NI: the iteration number.

NFG: the total number both of the gradient value and the function value.

Numerical results of Table 2 show that both of these two algorithms have a good efficiency for these practical problems. The iteration number, the number of the function value and the gradient value, and the CPU time will increase with the dimension becoming large for most of the problems. However, the CPU time does not become bigger but smaller, such as problems 4, 13, and 14 for Algorithm 2 and problems 1 and 16 for Algorithm 1; the reason may lie in the system of computer. The numerical results indicate that Algorithm 1 is competitive to Algorithm 2 especially for the CPU time for most of the tested problems. To directly show the performance of these two algorithms, the tool of Dolan and Moré [4] is used, and Figs. 1-3 show the profiles of them relative to NI, NFG, and Cputime, respectively. These three figures have the similar trend, then we only analyze Fig. 3 about the CPU time. Figure 3 shows that Algorithm 1 is better than Algorithm 2, Algorithm 1 goes beyond Algorithm 2 about 11\%, and Algorithm 1 has perfect robustness comparing with Algorithm 2. In a word, Algorithm 1 provides noticeable advantages.

\subsection{Fact engineering problem of the Muskingum model}

The subsection studies an application of the presented algorithm for a fact engineering problem, namely the well-known hydrologic engineering application problem often called 
Table 2 The numerical results of Algorithm 1 and Algorithm 2

\begin{tabular}{|c|c|c|c|c|c|c|c|}
\hline \multirow[t]{2}{*}{ Nr. } & \multirow[t]{2}{*}{ Dim } & \multicolumn{3}{|c|}{ Algorithm 1} & \multicolumn{3}{|c|}{ Algorithm 2} \\
\hline & & $\overline{\mathrm{NI}}$ & NFG & Cputime & $\mathrm{NI}$ & NFG & Cputime \\
\hline 1 & $\begin{array}{r}30,000 \\
60,000 \\
120,000\end{array}$ & $\begin{array}{l}2 \\
2 \\
2\end{array}$ & $\begin{array}{l}5 \\
5 \\
5\end{array}$ & $\begin{array}{l}0.0624 \\
0.124801 \\
0.109201\end{array}$ & $\begin{array}{l}168 \\
173 \\
180\end{array}$ & $\begin{array}{l}527 \\
544 \\
567\end{array}$ & $\begin{array}{c}3.681624 \\
7.86245 \\
16.083703\end{array}$ \\
\hline 2 & $\begin{array}{r}30,000 \\
60,000 \\
120,000\end{array}$ & $\begin{array}{l}21 \\
21 \\
21\end{array}$ & $\begin{array}{l}161 \\
161 \\
161\end{array}$ & $\begin{array}{l}1.981213 \\
3.962425 \\
7.456848\end{array}$ & $\begin{array}{r}97 \\
100 \\
104\end{array}$ & $\begin{array}{l}310 \\
319 \\
331\end{array}$ & $\begin{array}{r}4.851631 \\
9.703262 \\
18.579719\end{array}$ \\
\hline 3 & $\begin{array}{r}30,000 \\
60,000 \\
120,000\end{array}$ & $\begin{array}{l}2 \\
2 \\
2\end{array}$ & $\begin{array}{l}5 \\
5 \\
5\end{array}$ & $\begin{array}{l}0.0001 \\
0.0624 \\
0.124801\end{array}$ & $\begin{array}{l}4 \\
4 \\
4\end{array}$ & $\begin{array}{l}24 \\
24 \\
24\end{array}$ & $\begin{array}{l}0.078 \\
0.249602 \\
0.374402\end{array}$ \\
\hline 4 & $\begin{array}{r}30,000 \\
60,000 \\
120,000\end{array}$ & $\begin{array}{l}2 \\
2 \\
2\end{array}$ & $\begin{array}{l}14 \\
14 \\
14\end{array}$ & $\begin{array}{l}0.0624 \\
0.124801 \\
0.187201\end{array}$ & $\begin{array}{l}2 \\
2 \\
2\end{array}$ & $\begin{array}{l}6 \\
6 \\
6\end{array}$ & $\begin{array}{l}0.0624 \\
0.0001 \\
0.0624\end{array}$ \\
\hline 5 & $\begin{array}{r}30,000 \\
60,000 \\
120,000\end{array}$ & $\begin{array}{l}2 \\
2 \\
2\end{array}$ & $\begin{array}{l}15 \\
15 \\
15\end{array}$ & $\begin{array}{l}0.124801 \\
0.280802 \\
0.390002\end{array}$ & $\begin{array}{l}12 \\
15 \\
20\end{array}$ & $\begin{array}{l}35 \\
44 \\
59\end{array}$ & $\begin{array}{l}0.436803 \\
1.060807 \\
2.730017\end{array}$ \\
\hline 6 & $\begin{array}{r}30,000 \\
60,000 \\
120,000\end{array}$ & $\begin{array}{r}3 \\
43 \\
56\end{array}$ & $\begin{array}{r}27 \\
128 \\
167\end{array}$ & $\begin{array}{l}0.187201 \\
2.745618 \\
6.910844\end{array}$ & $\begin{array}{l}9 \\
4 \\
4\end{array}$ & $\begin{array}{l}28 \\
16 \\
16\end{array}$ & $\begin{array}{l}0.249602 \\
0.249602 \\
0.390003\end{array}$ \\
\hline 7 & $\begin{array}{r}30,000 \\
60,000 \\
120,000\end{array}$ & $\begin{array}{l}3 \\
3 \\
3\end{array}$ & $\begin{array}{l}17 \\
17 \\
17\end{array}$ & $\begin{array}{l}0.124801 \\
0.156001 \\
0.436803\end{array}$ & $\begin{array}{l}34 \\
34 \\
34\end{array}$ & $\begin{array}{l}101 \\
101 \\
101\end{array}$ & $\begin{array}{l}0.826805 \\
1.59121 \\
3.229221\end{array}$ \\
\hline 8 & $\begin{array}{r}30,000 \\
60,000 \\
120,000\end{array}$ & $\begin{array}{l}4 \\
4 \\
4\end{array}$ & $\begin{array}{l}20 \\
20 \\
20\end{array}$ & $\begin{array}{l}0.234002 \\
0.624004 \\
1.029607\end{array}$ & $\begin{array}{l}6 \\
6 \\
6\end{array}$ & $\begin{array}{l}50 \\
51 \\
50\end{array}$ & $\begin{array}{l}0.624004 \\
1.185608 \\
2.012413\end{array}$ \\
\hline 9 & $\begin{array}{r}30,000 \\
60,000 \\
120,000\end{array}$ & $\begin{array}{l}1097 \\
1439 \\
1500\end{array}$ & $\begin{array}{l}3290 \\
4316 \\
4499\end{array}$ & $\begin{array}{l}184.237181 \\
387.475284 \\
559.403986\end{array}$ & $\begin{array}{l}28 \\
28 \\
28\end{array}$ & $\begin{array}{l}85 \\
85 \\
85\end{array}$ & $\begin{array}{r}4.555229 \\
7.316447 \\
10.218066\end{array}$ \\
\hline 10 & $\begin{array}{r}30,000 \\
60,000 \\
120,000\end{array}$ & $\begin{array}{l}2 \\
2 \\
2\end{array}$ & $\begin{array}{l}5 \\
5 \\
5\end{array}$ & $\begin{array}{l}0.0624 \\
0.124801 \\
0.124801\end{array}$ & $\begin{array}{l}1500 \\
1500 \\
1500\end{array}$ & $\begin{array}{l}4504 \\
4504 \\
4504\end{array}$ & $\begin{array}{r}27.690178 \\
55.567556 \\
112.757523\end{array}$ \\
\hline 11 & $\begin{array}{r}30,000 \\
60,000 \\
120,000\end{array}$ & $\begin{array}{l}96 \\
86 \\
86\end{array}$ & $\begin{array}{l}287 \\
257 \\
257\end{array}$ & $\begin{array}{r}3.260421 \\
5.896838 \\
11.668875\end{array}$ & $\begin{array}{l}3 \\
3 \\
6\end{array}$ & $\begin{array}{l}19 \\
19 \\
25\end{array}$ & $\begin{array}{l}0.124801 \\
0.234002 \\
0.811205\end{array}$ \\
\hline 12 & $\begin{array}{r}30,000 \\
60,000 \\
120,000\end{array}$ & $\begin{array}{l}11 \\
11 \\
11\end{array}$ & $\begin{array}{l}122 \\
122 \\
122\end{array}$ & $\begin{array}{l}0.530403 \\
0.873606 \\
1.747211\end{array}$ & $\begin{array}{l}1500 \\
1500 \\
1500\end{array}$ & $\begin{array}{l}4505 \\
4505 \\
4505\end{array}$ & $\begin{array}{r}25.272162 \\
49.748719 \\
101.587851\end{array}$ \\
\hline 13 & $\begin{array}{r}30,000 \\
60,000 \\
120,000\end{array}$ & $\begin{array}{l}2 \\
2 \\
2\end{array}$ & $\begin{array}{l}14 \\
14 \\
14\end{array}$ & $\begin{array}{l}0.327602 \\
0.592804 \\
1.029607\end{array}$ & $\begin{array}{l}4 \\
3 \\
3\end{array}$ & $\begin{array}{r}21 \\
8 \\
8\end{array}$ & $\begin{array}{l}0.561604 \\
0.390003 \\
0.608404\end{array}$ \\
\hline 14 & $\begin{array}{r}30,000 \\
60,000 \\
120,000\end{array}$ & $\begin{array}{l}108 \\
149 \\
206\end{array}$ & $\begin{array}{l}323 \\
446 \\
617\end{array}$ & $\begin{array}{r}6.879644 \\
18.454918 \\
41.153064\end{array}$ & $\begin{array}{l}19 \\
10 \\
12\end{array}$ & $\begin{array}{r}164 \\
75 \\
93\end{array}$ & $\begin{array}{l}6.146439 \\
1.965613 \\
4.258827\end{array}$ \\
\hline 15 & $\begin{array}{r}30,000 \\
60,000 \\
120,000\end{array}$ & $\begin{array}{l}11 \\
11 \\
11\end{array}$ & $\begin{array}{l}122 \\
122 \\
122\end{array}$ & $\begin{array}{l}0.452403 \\
0.936006 \\
1.778411\end{array}$ & $\begin{array}{l}1500 \\
1500 \\
1500\end{array}$ & $\begin{array}{l}4503 \\
4503 \\
4503\end{array}$ & $\begin{array}{l}24.460957 \\
51.667531 \\
99.232236\end{array}$ \\
\hline 16 & $\begin{array}{r}30,000 \\
60,000 \\
120,000\end{array}$ & $\begin{array}{l}2 \\
2 \\
2\end{array}$ & $\begin{array}{l}5 \\
5 \\
5\end{array}$ & $\begin{array}{l}0.0624 \\
0.0156 \\
0.0624\end{array}$ & $\begin{array}{l}1500 \\
1500 \\
1500\end{array}$ & $\begin{array}{l}4517 \\
4517 \\
4517\end{array}$ & $\begin{array}{c}63.88241 \\
123.443591 \\
212.16136\end{array}$ \\
\hline
\end{tabular}


Figure 1 Performance profiles of Algorithm 1 and Algorithm 2 (NI)

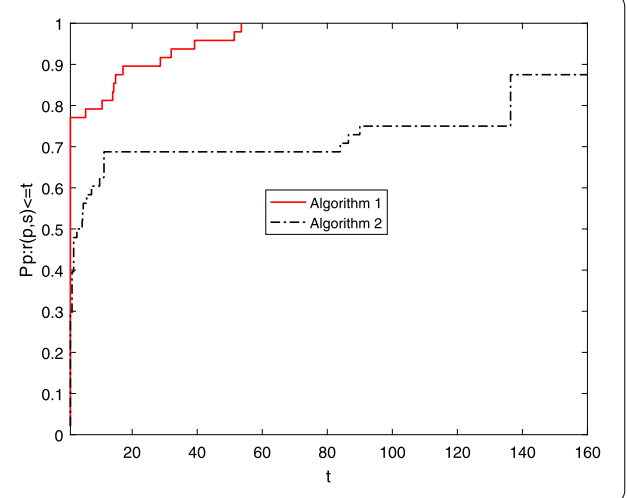

Figure 2 Performance profiles of Algorithm 1 and Algorithm 2 (NFG)

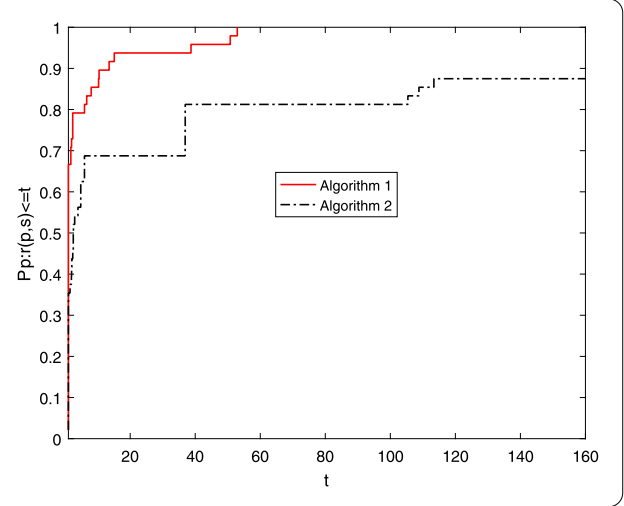

Figure 3 Performance profiles of Algorithm 1 and Algorithm 2 (Cputimes)

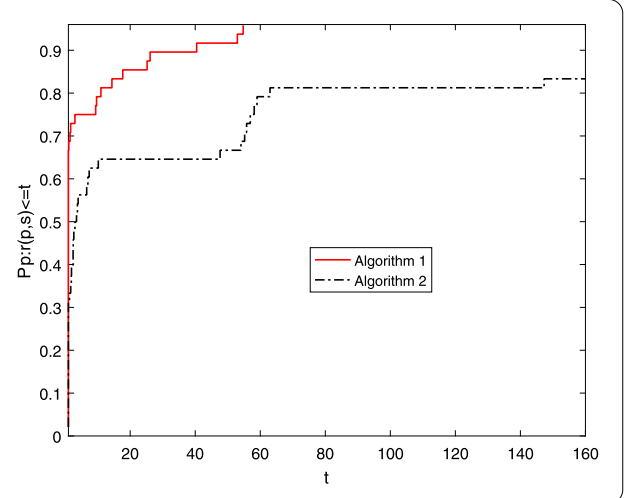

the parameter estimation problem of the nonlinear Muskingum model. The Muskingum model has the following definition.

Muskingum model [14]: The parameter estimation of the model is designed by

$$
\begin{aligned}
\min f\left(x_{1}, x_{2}, x_{3}\right)= & \sum_{i=1}^{n-1}\left(\left(1-\frac{\Delta t}{6}\right) x_{1}\left(x_{2} I_{i+1}+\left(1-x_{2}\right) Q_{i+1}\right)^{x_{3}}\right. \\
& -\left(1-\frac{\Delta t}{6}\right) x_{1}\left(x_{2} I_{i}+\left(1-x_{2}\right) Q_{i}\right)^{x_{3}}-\frac{\Delta t}{2}\left(I_{i}-Q_{i}\right) \\
& \left.+\frac{\Delta t}{2}\left(1-\frac{\Delta t}{3}\right)\left(I_{i+1}-Q_{i+1}\right)\right)^{2},
\end{aligned}
$$


Table 3 Results of these algorithms

\begin{tabular}{llll}
\hline Algorithms & $x_{1}$ & $x_{2}$ & $x_{3}$ \\
\hline BFGS [5] & 10.8156 & 0.9826 & 1.0219 \\
HIWO [14] & 13.2813 & 0.8001 & 0.9933 \\
Algorithm 1 & 11.1884 & 1.0034 & 0.9993 \\
\hline
\end{tabular}

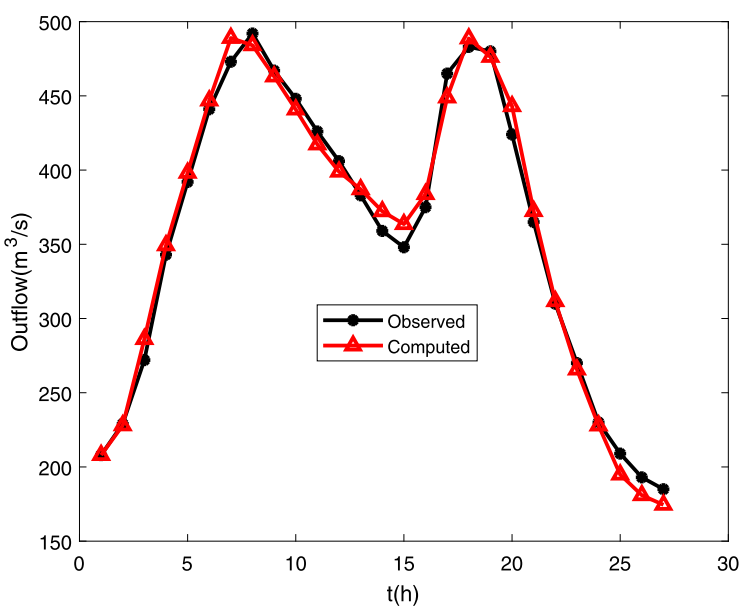

Figure 4 Performance of data in 1960

where $x_{1}$ is the storage time constant, $x_{2}$ is the weighting factor, and $x_{3}$ is an additional parameter; at time $t_{i}(i=1,2, \ldots, n), n$ denotes the total time number, $\Delta t$ is the time step, $I_{i}$ and $Q_{i}$ are the observed inflow discharge and observed outflow discharge, respectively. The Muskingum model, as a hydrologic routing method, is a popular model for flood routing, whose storage depends on the water inflow and outflow. This subsection uses actual observed data of the flood run-off process between Chenggouwan and Linqing of Nanyunhe in the 8 Haihe Basin, Tianjin, China, where $\Delta t=12(h)$. The detailed $I_{i}$ and $Q_{i}$ of the data of 1960, 1961, and 1964 can be found in [15]. In the numerical experiments, we set the initial point $x=[0,1,1]^{T}$. The tested results are listed in Table 3 .

Figures 4-6 are the data curves of 1960, 1961, and 1964 about the observed flows and computed flows by Algorithm 1 for estimating the parameters of the nonlinear Muskingum model, which shows that the given algorithm has good approximation for these data and Algorithm 1 is effective for the nonlinear Muskingum model. The results of Table 3 and Figs. 4-6 tell us at least two conclusions: (1) Algorithm 1 can be successfully used for solving the nonlinear Muskingum model because of its good approximation; (2) the points $x_{1}, x_{2}$, and $x_{3}$ obtained by Algorithm 1 are different from the BFGS method and the HIWO method, which shows that the Muskingum model may be have several optimum approximated points.

\section{Conclusion}

This paper studies the proof method and proposes a simple proof technique to get the global convergence of the known algorithm in the paper [28]. The following conclusions are obtained by this paper: 


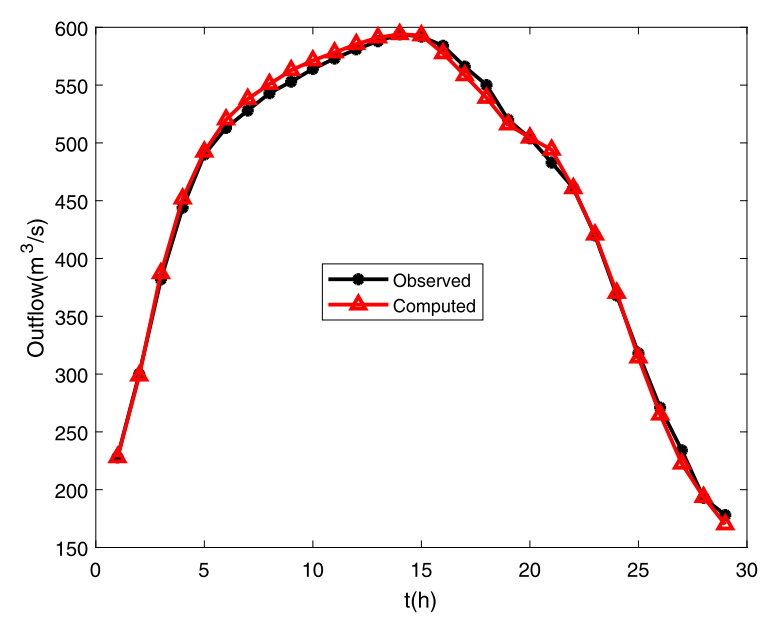

Figure 5 Performance of data in 1961

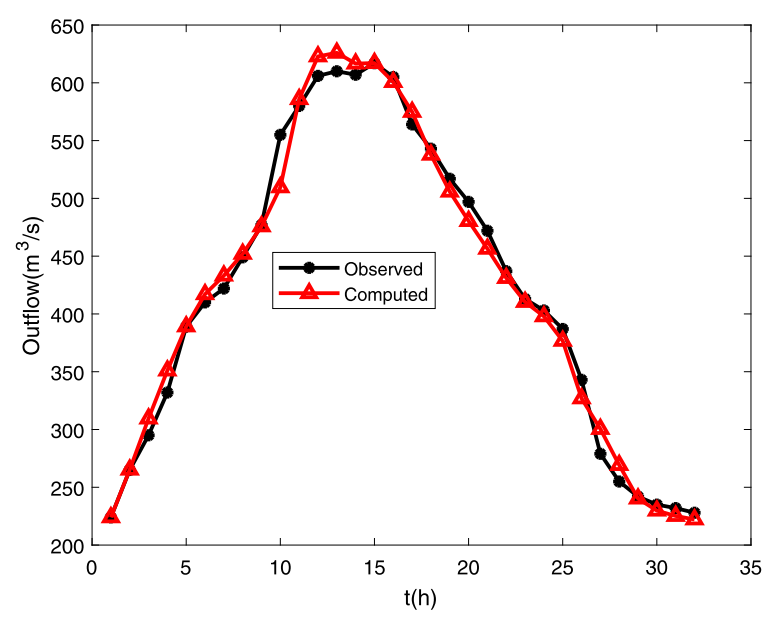

Figure 6 Performance of data in 1964

(1) This paper gives a new proof method for the paper [28] and gets the same result under weaker conditions. This new proof technique is more simple than those of the paper [28].

(2) More larger-scale dimension problems are done comparing with [28] to show that the given algorithm is competitive to the normal algorithm. The nonlinear Muskingum model coming from the fact engineering problem is done by the given algorithm to estimate its parameters, which demonstrates that Algorithm 1 is very successful.

(3) One interesting question and work is whether there exist some other proof methods to get the global convergence of Algorithm 1, which is one of the works of ours in the future. 


\section{Funding}

This work is supported by the National Natural Science Foundation of China (Grant No. 11661009), the Guangxi Science Fund for Distinguished Young Scholars (No. 2015GXNSFGA139001), and the Guangxi Natural Science Key Fund (No. 2017GXNSFDA198046).

\section{Competing interests}

There is no potential conflicts of interest.

\section{Authors' contributions}

XL organized this whole paper, TY wrote some parts of the proof, and XW did the experiments and wrote some parts of the proof. All authors read and approved the final manuscript.

\section{Author details}

${ }^{1}$ College of Mathematics and Information Science, Guangxi University, Nanning, P.R. China. ${ }^{2}$ School of Finance and Economics, Nanning College For Vocational Technology, Nanning, P.R. China. ${ }^{3}$ School of Mathematical Sciences, Dalian University of Technology, Dalian, P.R. China.

\section{Publisher's Note}

Springer Nature remains neutral with regard to jurisdictional claims in published maps and institutional affiliations.

Received: 11 March 2019 Accepted: 1 July 2019 Published online: 15 July 2019

\section{References}

1. Bongartz, I., Conn, A.R., Gould, N.I., Toint, P.L.: CUTE: constrained and unconstrained testing environment. ACM Trans. Math. Softw. 21, 123-160 (1995)

2. Dai, Y.: Analysis of conjugate gradient methods. Ph.D. thesis, Institute of Computational Mathematics and Scientific/Engineering Computing, Chese Academy of Sciences (1997)

3. Dai, Y.: Convergence properties of the BFGS algorithm. SIAM J. Optim. 13, 693-701 (2003)

4. Dolan, E.D., Moré, J.J.: Benchmarking optimization software with performance profiles. Math. Program. 91, 201-213 (2002)

5. Geem, Z.W.: Parameter estimation for the nonlinear Muskingum model using the BFGS technique. J. Hydrol. Eng. 132, 474-478 (2006)

6. Gilbert, J.C., Nocedal, J.: Global convergence properties of conjugate gradient methods for optimization. SIAM J. Optim. 2, 21-42 (1992)

7. Gould, N.I., Orban, D., Toint, P.L.: CUTEr and SifDec: a constrained and unconstrained testing environment, revised. ACM Trans. Math. Softw. 29, 373-394 (2003)

8. Hager, W., Zhang, H.: A new conjugate gradient method with guaranteed descent and an efficient line search. SIAM J. Optim. 16, 170-192 (2005)

9. Hager, W., Zhang, H.: Algorithm 851: CG DESCENT, a conjugate gradient method with guaranteed descent. ACM Trans. Math. Softw. 32, 113-137 (2006)

10. Mingqi, X., Rădulescu, V.D., Zhang, B.: Combined effects for fractional Schrödinger-Kirchhoff systems with critical nonlinearities. ESAIM Control Optim. Calc. Var. 24, 1249-1273 (2018)

11. Mingqi, X., Rădulescu, V.D., Zhang, B.: Nonlocal Kirchhoff diffusion problems: local existence and blow-up of solutions. Nonlinearity 31, 3228-3250 (2018)

12. Mingqi, X., Rădulescu, V.D., Zhang, B.: Fractional Kirchhoff problems with critical Trudinger Moser nonlinearity. Calc. Var. Partial Differ. Equ. 58, 57 (2019). https://doi.org/10.1007/s00526-019-1499-y

13. Mingqi, X., Rădulescu, V.D., Zhang, B.: A critical fractional Choquard-Kirchhoff problem with magnetic field. Commun. Contemp. Math. 21(4), 185004 (2019)

14. Ouyang, A., Liu, L., Sheng, Z., Wu, F.: A class of parameter estimation methods for nonlinear Muskingum model using hybrid invasive weed optimization algorithm. Math. Probl. Eng. 2015, Article ID 573894 (2015)

15. Ouyang, A., Tang, Z., Li, K., Sallam, A., Sha, E.: Estimating parameters of Muskingum model using an adaptive hybrid PSO algorithm. Int. J. Pattern Recognit. Artif. Intell. 28, Article ID 1459003 (2014)

16. Polak, E.: The conjugate gradient method in extreme problems. Comput. Math. Math. Phys. 9, 94-112 (1969)

17. Polak, E., Ribière, G.: Note sur la convergence de directions conjugees. Rev. Fr. Inform. Rech. Oper. 3, 35-43 (1969)

18. Powell, M.J.D.: Nonconvex minimization calculations and the conjugate gradient method. In: Numerical Analysis. Lecture Notes in Mathematics, vol. 1066, pp. 122-141. Spinger, Berlin (1984)

19. Powell, M.J.D.: Convergence properties of algorithm for nonlinear optimization. SIAM Rev. 28, 487-500 (1986)

20. Sun, Y.: Indirect boundary integral equation method for the Cauchy problem of the Laplace equation. J. Sci. Comput. 71, 469-498 (2017)

21. Wei, Z., Yao, S., Liu, L.: The convergence properties of some new conjugate gradient methods. Appl. Math. Comput $183,1341-1350(2006)$

22. Yuan, G.: Modified nonlinear conjugate gradient methods with sufficient descent property for large-scale optimization problems. Optim. Lett. 3,11-21 (2009)

23. Yuan, G., Lu, X.: A modified PRP conjugate gradient method. Ann. Oper. Res. 166, 73-90 (2009)

24. Yuan, G., Lu, X., Wei, Z.: A conjugate gradient method with descent direction for unconstrained optimization. J. Comput. Appl. Math. 233, 519-530 (2009)

25. Yuan, G., Meng, Z., Li, Y.: A modified Hestenes and Stiefel conjugate gradient algorithm for large-scale nonsmooth minimizations and nonlinear equations. J. Optim. Theory Appl. 168, 129-152 (2016)

26. Yuan, G., Sheng, Z., Wang, B., Hu, W., Li, C.: The global convergence of a modified BFGS method for nonconvex functions. J. Comput. Appl. Math. 327, 274-294 (2018) 
27. Yuan, G., Wei, Z., Li, G.: A modified Polak-Ribière-Polyak conjugate gradient algorithm for nonsmooth convex programs. J. Comput. Appl. Math. 255, 86-96 (2014)

28. Yuan, G., Wei, Z., Lu, X.: Global convergence of the BFGS method and the PRP method for general functions under a modified weak Wolfe-Powell line search. Appl. Math. Model. 47, 811-825 (2017)

29. Yuan, G., Wei, Z., Yang, Y.: The global convergence of the Polak-Ribière-Polyak conjugate gradient algorithm under inexact line search for nonconvex functions. J. Comput. Appl. Math. 362 262-275 (2019). https://doi.org/10.1016/j.cam.2018.10.057

30. Yuan, G., Zhang, M.: A three-terms Polak-Ribière-Polyak conjugate gradient algorithm for large-scale nonlinear equations. J. Comput. Appl. Math. 286, 186-195 (2015)

Submit your manuscript to a SpringerOpen ${ }^{\circ}$ journal and benefit from:

- Convenient online submission

- Rigorous peer review

- Open access: articles freely available online

- High visibility within the field

- Retaining the copyright to your article

Submit your next manuscript at $\gg$ springeropen.com 